\title{
Frequency of grading of complications using modified clavien classification system after transurethral resection of prostate.
}

\footnotetext{
1. MBBS,

Registrar Urology PKLI, Lahore.

2. MBBS, FCPS (Urology)

Assistant Professor Urology and

Renal Transplant Department

Pir Abdul Qadir Shah Institute of

Medical Sciences, Gambat.

3. MBBS, MS (General Surgery)

Senior Clinical Fellow Organ

Transplant Department

Pir Abdul Qadir Shah Institute of Medical Sciences, Gambat.

4. MBBS, FCPS (General Surgery),

MRCPS (Glasgow)

Senior Clinical Fellow

Pir Abdul Qadir Shah Institute of

Medical Sciences, Gambat, Khair Pur Mirs.

5. MBBS, FCPS (Urology)

Registrar Urology Department SUIT Karachi.

6. MBBS, FCPS (Urology)

Assistant Professor Urology

Department

SUIT Karachi.
}

Correspondence Address:

Dr. Kaleem Ullah

Pir Abdul Qadir Shah Institute of

Medical Sciences, Gambat.

drkaleempk@gmail.com

Article received on:

$12 / 11 / 2020$

Accepted for publication:

$10 / 01 / 2021$

\section{INTRODUCTION}

Benign prostatic hyperplasia (BPH) is the leading cause of lower urinary tract symptoms (LUTS) in males and affects almost up to 210 million men worldwide. ${ }^{1}$ Approximately $50 \%$ and $75 \%$ of men will be having histologically $\mathrm{BPH}$ at 50 and 80 years of age respectively, and almost $50 \%$ of them will clinically present with lower urinary tract symptoms symptoms. ${ }^{2}$

Transurethral resection of the prostate (TURP) is considered the "golden standard" procedure for $\mathrm{BPH}$ management. With advancing technology and training the complications of TURP has reduced a lot. However, like other most surgical procedures, TURP is not without complications. ${ }^{3}$ In a prospective multicenter study perioperative morbidity rate of $11.1 \%$ and mortality rate of $0.1 \%$ was published. ${ }^{4}$ Also another study showed an overall complication as $40 \% .^{5}$

Currently, various scoring system are in use for predicting post TURP complications, with no known ideal scoring system. ${ }^{6}$ The Modified Clavien Classification System (MCCS), has been suggested for grading of post-operative surgical complications. In MCCS, the complications are divided into five grades (Grade I to Grade V) from minor to major complications. ${ }^{7}$

Mitropoulus et al in a systematic review showed that MCCS or Clavien Dindo classification system a simple, reliable, and validated tool for assessing, reporting and grading of post urologic 
surgical complications and thus recommended this classification system for post urological complications among other grading systems considered. ${ }^{8}$

MCCS is increasingly become popular in field of urology .Very few studies have used MCCS for grading the post-operative complications of TURP, also there is a huge variability in the literature with MCCS grading post-TURP complications.

The rationale behind our study was to determine the frequency of severity of Post- TURP complications in our population using MCCS. This study will be helpful in understanding the appropriateness of MCCS in grading TURP complications. The results will be shared with community.

\section{MATERIAL \& METHODS}

This Descriptive study was carried at Urology Department, Sindh Institute of Urology and Transplantation, Karachi, from 26 ${ }^{\text {th }}$ May, 2019 to $25^{\text {th }}$ Nov 2019. Total duration of study was 6 months. Total of 162 cases were included in this study through non-probability consecutive sampling technique.

Patients who were advised TURP for $\mathrm{BPH}$ with prostatic volume of $>40$ gram, age range $>50$ to $<80$ years, with ASA status I-III were included in this study.

Patients with previous history of bladder neck, prostate or pelvic surgery were excluded from this study.

After approval from hospital ethical, verbal and written informed consent was taken from all patients. All TURP procedures were done by consultant urologists.

Data of Post-operative complications was collected up to 3 months post TURP in out-patient department, and categorization of complications was done by MCCS.

Grade-I: Any deviation from the normal postoperative course without the need for pharmacological treatment or surgical, endoscopic and radiological interventions i-e fever (>100F), transient hematuria (that persist for $<48$ hours and then resolves spontaneously), catheter blockage and failed voiding trial. Therapeutic drugs allowed are anti-emetics, analgesics, antipyretics, and physiotherapy.

Grade-II: Complications requiring treatment with medications other than mentioned for above grade I complications i-e hematuria requiring blood transfusion and urinary tract infection requiring antibiotics.

Grade-III: Complications requiring management with endoscopic, surgical or radiologic intervention i-e bladder perforation and urethral stenosis.

Grade-IV: Life-threatening complications needing treatment intensive care unit i-e pulmonary embolism, myocardial infarction, uro-sepsis and transurethral syndrome.

Grade-V: Death within one month of procedure.

Patient's demographicsage, gender and operative data like prostate size/volume, operative duration, mean prostatic tissue resected and hospital stay was collected. All this information was recorded on a pre-designed Performa.

All the data was entered and analyzed in SPSS version 20. Continuous variables such as age, prostate size/volume, operative duration, prostate volume resected and duration of hospitalization was presented as mean (SD), and categorical variables such as MCCS grading was done in frequencies and percentage form. Effect modifiers such as age, prostate size/volume, and operative duration were controlled by stratification. Chisquare was also applied test Post-stratification for determining association of the effect modifiers with grading complications, while taking P-value of $<0.05$ as significant.

\section{RESULTS}

Mean age was 63.32 \pm 8.36 years (range of 50 to 70 years). Mean prostate volume of patients was $56.99 \pm 13.25$ grams. (Range was 40 to 88 ). 
Mean operation time was $26.55 \pm 9.46$ minutes. Minimum operation time was 10 mins and maximum was 50 mins. Mean prostatic tissue removed was $16.75 \pm 12.09$ grams. Minimum was 05 grams and maximum was 50 grams. Mean duration of hospitalization was $1.27 \pm 0.60$ days. Minimum duration was 01 and maximum were 04 days. Table-I.

Frequency of MCCS grading showed grade I complication in 06 (3.70\%) patients; grade II in $03(1.85 \%)$ patients, grade IV in 01 (0.62\%) patients. While no complication observed in remaining 152 (93.83\%) cases (Figure-1) and overall complication was $6.17 \%$.

Stratification of age with two age groups, 5060 and 61-70 years over MCCS was done. The difference was statistically insignificant with Pvalue of 0.334 . Table-II.

Stratification of mean prostate volume over MCCS between two groups was done, $1^{\text {st }}$ group with 40-50-gram and other group with mean prostate volume $>50 \mathrm{gm}$. This difference was also statistically not significant with $\mathrm{p}$ - value of 0.193. Table-III.

Similarly, stratification was also performed on the basis of mean prostate tissue removed, operation time and hospital stay and no signification association was found with MCCS. Table-IV, V, VI.

\begin{tabular}{|c|c|c|c|}
\hline \multicolumn{2}{|c|}{ Variable } & Mean & Range \\
\hline \multicolumn{2}{|c|}{ Age(years) } & $63.32 \pm 8.53$ & $50-70$ \\
\hline \multicolumn{2}{|c|}{ Prostate volume(gm) } & $56.99 \pm 13.25$ & $30-88$ \\
\hline \multicolumn{2}{|c|}{ Operation Time(mins) } & $26.55 \pm 9.46$ & $10-50$ \\
\hline \multicolumn{2}{|c|}{ Prostate Tissue Removed(gm) } & $16.75 \pm 12.09$ & $05-50$ \\
\hline \multicolumn{2}{|c|}{ Hospital stay (days). } & $1.27 \pm 0.60$ & $01-04$ \\
\hline \multicolumn{4}{|c|}{ Table-I. } \\
\hline \multirow{2}{*}{$\begin{array}{l}\text { MCC Grading } \\
\text { Complications }\end{array}$} & \multicolumn{2}{|c|}{ Age Group } & \multirow{2}{*}{$\begin{array}{c}\text { P- } \\
\text { Value }\end{array}$} \\
\hline & 50-60 Years & 61-70 Years & \\
\hline Grade I & 01 & 05 & \multirow{6}{*}{0.33} \\
\hline Grade II & 02 & 01 & \\
\hline Grade III & 00 & 00 & \\
\hline Grade IV & 00 & 01 & \\
\hline Grade V & 00 & 00 & \\
\hline Nil & 70 & 82 & \\
\hline
\end{tabular}

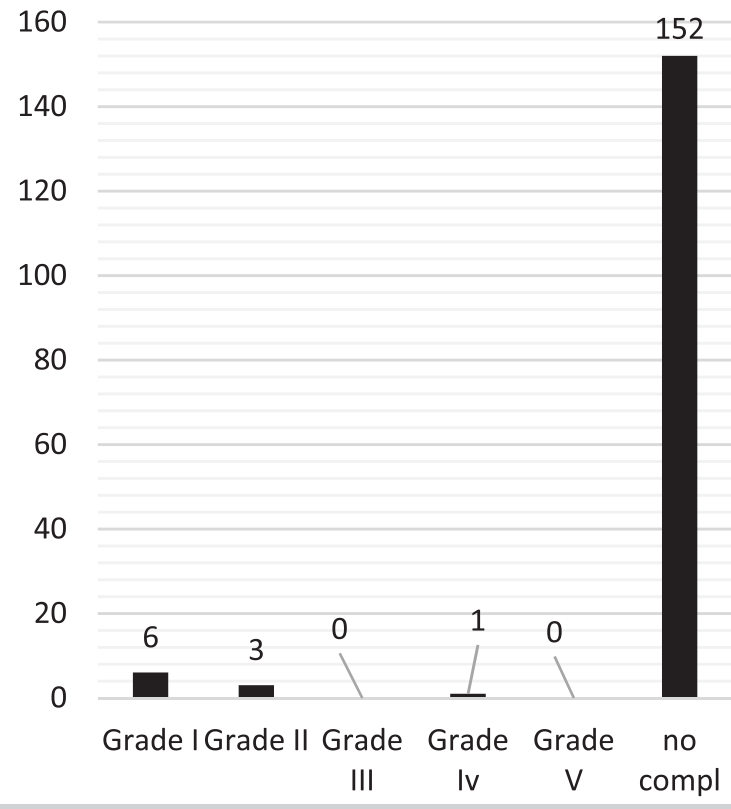

Figure-1. Frequency of MCCS Grading Complications.

\begin{tabular}{|c|c|c|c|}
\hline \multirow{2}{*}{$\begin{array}{l}\text { MCC Grading } \\
\text { Complications }\end{array}$} & \multicolumn{2}{|c|}{ Mean Prostate Volume } & \multirow{2}{*}{ P-Value } \\
\hline & $40-50 \mathrm{gm}$ & $>50 \mathrm{gm}$ & \\
\hline Grade I & 00 & 06 & \multirow{6}{*}{0.193} \\
\hline Grade II & 01 & 02 & \\
\hline Grade III & 00 & 00 & \\
\hline Grade IV & 00 & 01 & \\
\hline Grade V & 00 & 00 & \\
\hline Nil & 62 & 90 & \\
\hline
\end{tabular}

\begin{tabular}{|l|c|c|c|}
\hline \multicolumn{1}{|c|}{$\begin{array}{l}\text { MCC Grading } \\
\text { Complications }\end{array}$} & \multicolumn{2}{|c|}{ Operation Time } & \multirow{2}{*}{ P-Value } \\
\hline Grade I & $\mathbf{1 0}$-20 Mins & $\mathbf{2 1 - 5 0}$ Mins & \\
\hline Grade II & 00 & 06 & \\
\hline Grade III & 01 & 02 & \\
\hline Grade IV & 00 & 00 & \multirow{2}{*}{0.10} \\
\hline Grade V & 00 & 01 & \\
\hline Nil & 00 & 00 & \\
\hline
\end{tabular}

Table-IV. Stratification of operation time to determine the association with MCC grading complications.

\begin{tabular}{|c|c|c|c|}
\hline \multirow{2}{*}{$\begin{array}{l}\text { MCC Grading } \\
\text { Complications }\end{array}$} & \multicolumn{2}{|c|}{$\begin{array}{c}\text { Mean Prostate Tissue } \\
\text { Removed }\end{array}$} & \multirow[t]{2}{*}{ P-Value } \\
\hline & 05-12 gm & $>13 \mathrm{gm}$ & \\
\hline Grade I & 01 & 05 & \multirow{6}{*}{0.29} \\
\hline Grade II & 02 & 01 & \\
\hline Grade III & 00 & 00 & \\
\hline Grade IV & 01 & 00 & \\
\hline Grade V & 00 & 00 & \\
\hline $\mathrm{Nil}$ & 67 & 85 & \\
\hline
\end{tabular}




\begin{tabular}{|l|c|c|c|}
\hline \multirow{2}{*}{$\begin{array}{l}\text { MCC Grading } \\
\text { Complications }\end{array}$} & \multicolumn{2}{|c|}{ Hospital stay } & \multirow{2}{*}{ P-Value } \\
\cline { 1 - 3 } Grade I & 01 & 02-04 Days & \\
\hline Grade II & 00 & 05 & \\
\hline Grade III & 00 & 00 & \multirow{2}{*}{0.10} \\
\hline Grade IV & 00 & 01 & \\
\hline Grade V & 00 & 00 & \\
\hline Nil & 126 & 26 & \\
\hline
\end{tabular}

Table-VI. Stratification of hospital stay to determine the association with MCC grading complications.

\section{DISCUSSION}

This study was subjected to evaluate MCCS applicability in grading post-operative TURP complications in BPH patients, rather than on reporting the negative procedural outcomes, which has been thoroughly documented long ago, in large prospective and retrospective multicentric cohorts. ${ }^{4,9,10,11}$

Due to lack of uniformity in reporting negative surgical outcomes, the need of a standardized system for reporting post-operative complications following urological procedures has been realized. ${ }^{12}$

For grading of post-operative complications, Clavien et al. described a four-tiered classification system in $1992 .{ }^{13}$ In 2004, Dindo et al. revised this classification and divided this into five grades. This classification is proclaimed as Clavien-Dindo classification or modified Clavian classification system (MCCS). According to the authors, this classification is unequivocal, more reproducible, and is an imperative tool for quality assessment of surgical outcomes. In this complication, Grade 1 and 2 are minor but Grade 3-5 are the major complications. ${ }^{14}$ Recentlythis classification system has been adopted by several urologists and is currently being used for various oncological, and endo-urological procedures. ${ }^{15,16}$ The MCCS has been suggested a standard system for reporting post-operative complications, and should be applied accordingly to enhance the quality of related literature. ${ }^{17}$

Usually the minor postoperative problems are usually under reported, and the use of such a standardized system for ranking post-operative complications, prevents negative reporting by maximum detection. Furthermore, such a system has other potential advantages, i.e. increases stability in results reporting, allow longitudinal comparisons of these results with other centers, and helps in conduction of adequate metaanalyses. ${ }^{18}$

In current study mean age of patient is $63.32 \pm 8.36$ years, which is in line to the mean age in other related studies which reported mean ages of $66.1,65 \pm 5.8,67.2,66.1 \pm 8.6$, and $67.07 \pm 9.38$ among patients. . $^{19,20,21}$

Furthermore, Mamoulakis et al. ${ }^{22}$ published $15.7 \%$ of overall complication rate, which is quite higher in comparison to our study. We reported an overall recurrence of complication as $6.17 \%$. Agrawal et al. ${ }^{23}$ published an overall complication rate of $34.4 \%$ which is also higher that what we reported.

Study conducted by Mandal et al. found grade I complications in $22.2 \%$ patients, grade || in $5.5 \%$ patients, grade III in $4.4 \%$, Grade IV in $2.7 \%$ and Grade $V$ complications in $0.4 \%$ of patients. Main bulk of complications almost (90\%) was constituted by Grades I, II and III. ${ }^{7}$ While in current study, grade I complications found in 06 (3.70\%) patients, grade II in $03(1.85 \%)$ patients, grade III in 00 patients, grade IV in $01(0.62 \%)$ patients and grade $\mathrm{V}$ in just 00 patient. While no complication observed in remaining 152 (93.83\%) patients.

In another study $59.1 \%$ were grade I and $29.5 \%$ were grade II. Higher grade complications. Grade III were $2.3 \%$, grade IV $6.8 \%$ and grade V were $2.3 \%$ with single death. ${ }^{24}$

In current study, all patients were monitored for first three months postoperatively. Therefore, are rare longer term post TURP complications were missed, and considered as a limitation of current study.

\section{CONCLUSION}

Clavien-Dindo classification system can be easily applied by urologists to grade the post- 
operative transurethral resection of prostate (TURP) complications. We observed that TURP is a very safe procedure for surgical management of benign prostatic hyperplasia, and is having low morbidity and mortality according to MCCS.

Copyright(C 10 Jan, 2021.

\section{REFRENCES}

1. Verhamme KM, Dieleman JP, Bleumink GS, Van der Lei J, Sturkenboom MC. Incidence and prevalence of lower urinary tract symptoms suggestive of benign prostatic hyperplasia in primary care-the Triumph project. Eur Urol. 2002; 42(4):323-8.

2. Guess HA, Arrighi HM, Metter EJ, Fozard JL. Cumulative prevalence of prostatism matches the autopsy prevalence of benign prostatic hyperplasia. The Prostate. 1990; 17(3):241-6.

3. Rassweiler J, Teber D, Kuntz R, Hofmann R. Complications of transurethral resection of the prostate (TURP)-incidence, management, and prevention. Eur Urol 2006; 50:969-79.

4. Reich O, Gratzke C, Bachmann A, Seitz M, Schlenker $B$, Hermanek P, et al. Morbidity, mortality and early outcome of transurethral resection of the prostate: A prospective multicenter evaluation of 10,654 patients. J Urol 2008; 180:246-9.

5. Frede T, Rassweiler JJ. Management of postoperative complications following TURP. In Practical Tips in Urology. Springer, London. 2017: p493-501.

6. Öğreden E, Oğuz U, Demirelli E, Benli E, Sancak EB, Gülpinar MT, et al. Categorization of ureteroscopy complications and investigation of associated factors by using the modified Clavien classification system. Turk J Med Sci. 2016; 46(3):686-94.

7. Mandal S, Sankhwar SN, Kathpalia R, Singh MK, Kumar M, Goel A, et al. Grading complications after transurethral resection of prostate using modified Clavien classification system and predicting complications using the Charlson comorbidity index. Int urol Nephrol. 2013; 45(2):347-54.

8. Mitropoulus D, Artibani W, Graefen M, Remzi M, Roupret M, Truss M, et al. Reporting and grading of complications after urological surgical procedures: An adhoc EAU guidelines Panel assessment and recommendations. Eur Urol 2012; 612:341-9.

9. Holtgrewe HL, Valk $\mathrm{WL}$. Factors influencing the mortality and morbidity of transurethral prostatectomy: A study of 2, 015 cases. J Urol. 1962; 87:450-459.
10. Melchior J, Valk WL, Foret JD, Mebust WK. Transurethral prostatectomy: Computerized analysis of 2, 223 consecutive cases. J Urol. 1974; 112:634-642.

11. Mebust WK, Holtgrewe HL, Cockett AT, Peters PC. Transurethral prostatectomy: immediate and postoperative complications. A cooperative study of 13 participating institutions evaluating 3, 885 patients. J Urol. 1989; 141:243-247.

12. Donat SM. Standards for surgical complication reporting in urologic oncology: Time for a change. Urology. 2007; 69:221-225. doi: 10.1016/j. urology.2006.09.056.

13. Clavien PA, Sanabria JR, Strasberg SM. Proposed classification of complications of surgery with examples of utility in cholecystectomy. Surgery. 1992; 111:518-526.

14. Dindo D, Demartines N, Clavien PA. Classification of surgical complications: A new proposal with evaluation in a cohort of 6336 patients and results of a survey. Ann Surg. 2004; 240(2):205.

15. Ibrahim AK. Reporting ureteroscopy complications using the modified clavien classification system. Urol Ann. 2015; 7(1):53-7.

16. Kumar U, Tomar V, Yadav SS, Priyadarshi S, Vyas N, Agarwal N, et al. Stone score versus Guy's Stone Score-prospective comparative evaluation for success rate and complications in percutaneous nephrolithotomy. Urol Ann. 2018; 10(1):76-81.

17. Ramasamy R, Afaneh $C$, Katz $M$, Chen X, Aull MJ, Leeser DB, et al. Comparison of complications of laparoscopic versus laparoendoscopic single site donor nephrectomy using the modified Clavien grading system. J Urol. 2011 Oct; 186(4):1386-90.

18. Sagen E, Namnuan RO, Hedelin H, Nelzén O, Peeker R. The morbidity associated with a TURP procedure in routine clinical practice, as graded by the modified Clavien-Dindo system. Scand J Urol. 2019:1-6.

19. Dawan D, Rafindadi AH, Kalayi GD. Benign prostate hyperplasia and prostate cancer in native Africans. BJU Int 2000; 85:1074-7. Back to cited text no. 10.

20. Chukwujama NO, Oguike T, Azike J. Transurethral resection of the prostate: A 3 year experience. Niger J Surg 2011; 17:15-8. Back to cited text no. 11.

21. Alhasan SU, Aji SA, Mohammed AZ, Malami S. Transurethral resection of the prostate in Northern Nigeria, problems and prospects. BMC Urol 2008; 8:18. 
22. Mamoulakis C, Efthimiou I, Kazoulis S, Christoulakis I, Sofra F. The modified Clavien classification system: A standardized platform for reporting complications in transurethral resection of the prostate World. J Urol 2011; 29:205-10.

23. Agrawal M, Kumar M, Pandey S, Aggarwal A, Sankhwar $S$. Changing profiles of patients undergoing transurethral resection of the prostate over a decade: A single-center experience. Urol Ann 2019; 11:270-5.
24. Mamoulakis, Charalampos et al. "The modified Clavien classification system: A standardized platform for reporting complications in transurethral resection of the prostate." World journal of urology vol. 29,2 (2011): 205-10. doi:10.1007/s00345-010-0566-y.

\begin{tabular}{|c|c|c|c|}
\hline \multicolumn{4}{|c|}{ AUTHORSHIP AND CONTRIBUTION DECLARATION } \\
\hline Sr. \# & Author(s) Full Name & Contribution to the paper & Author(s) Signature \\
\hline 1 & Aadil Chaudhary & Study conception and design. & \\
\hline 2 & Zulfiqar Ahmed & $\begin{array}{l}\text { Statsitical expertise and result } \\
\text { compilation. }\end{array}$ & \\
\hline 3 & Bilal Ahmed & Drafting of manuscript. & 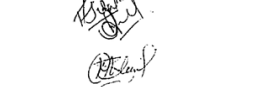 \\
\hline 4 & Kaleem Ullah & Acquisition, Analysis of data. & \\
\hline 5 & Mehran Khan Lashari & Review of Discussion. & \\
\hline 6 & Usman Qamar & Interpretation of data. & vis \\
\hline
\end{tabular}

